\title{
『日本哲学思想資料集』について
}

Seungchul KIM(金承哲: Professor of the Faculty of Humanities, Nanzan University)

冈 sechkim@gmail.com

(日本) 南山大学人文学部教授・南山宗教文化研究所所長。キリスト教神学、宗教間対話、宗教と文学。”A Pluralistic Pluralism : With Some Remarks on Fallibilism" The Grace of Being Fallible in Philosophy. Theology, and Religion ed. by Thomas John Hastings and Knut-Willy Saether. Palgrave Macmillan, 2020, 『遠藤周作と探偵小説 ——痕跡と追跡の文学』(南山大学学術叢書) (名古屋 : 教文館. 2019), “Der philosophische Glaube angesichts des religiösen Pluralismus" Andreas Cesana (Hrsg.) Kulturkonflikte und Kommunikation : Zur Aktualität von Jaspers' Philosophie Königshausen \& Neuman, 2016.『神と遺伝子一遺伝子工学時代におけるキリスト教』(東 京：教文館. 2009)等。

\section{On the Korean translation of Japanese Philosophy}

The Nanzan Institute for Religion and Culture in Nagoya, Japan, published Japanese Philosophy: A Sourcebook, which was translated into Korean and published by Bogosa in 2021 as 일본철학사상자료집 (Ilbon Cheolhak Sasangjaryo Chib). The translation was carried out through the cooperation of 19 Korean scholars who specialize in Japanese religion, philosophy, literature, and so on, who are mainly affiliated with Korea University's Global Institute for Japanese Studies. We hope that this work will help many Koreans understand and access the sources of Japanese religious and philosophical thought.

Keywords Japanese Philosophy：A Sourcebook(日本哲学思想資料集), translation into Korean(韓国語翻訳), Japanese religion and philosophy(日本宗教と哲学), Nanzan Institute for Religion and Culture(南山宗教文化研究所) 
日本の宗教・哲学思想は、どれほど韓国に紹介されまた理解されているの か。このような質問は、答えようがないほどあまりにも漠然としたものではあ ろう。また、たとえその質問に対する答えが否定的なものであると診断された としても、何かの一つの試みによってその問題点をまとめて解消寸るのは、い うまでもなく不可能なものである。こうした意味では、『日本哲学思想資料集』 (以下『資料集』とする)が韓国語に翻訳され出版されたことについても、日本の思 想について紹介する一冊の書籍が出版されたというふうに整理されてしまうか もしれない。

しかしながら、『資料集』の中身をみると、やはり今まで日本思想を紹介して くれた書籍とは、異なる次元のものとして扱ってもいいとも思われる。なぜな らば、『資料集』は、古代の聖徳太子より現代の哲学思想までを網羅したものであ り、それぞれの思想家より抜粋された原文には、元編集者たちの解説文がついて いるからである。以下においては、まずこの書籍が出版されるまでの経緯につ いて略述したあと、この本の内容についても簡潔に紹介することにする。（以下 の内容の一部は『日本哲学思想資料集』の韓国語訳として出版された『일본철학사상 자료집』(2021年、보고사、1062+xxiv頁)に揭載されている、本人の『『일본철학사 상자료집』의 한국어 번역과 출판에 즈음하여」からの転載された内容を含んでい ることを書いておく。)

『日本哲学思想資料集』の翻訳・出版は、南山大学 (日本、名古屋市所在)の「南山 大学第4期国際化推進事業」の支援を受け、南山宗教文化研究所が推進してきた ＜日本の思想と文化を国際的に知らせるための研究拠点の確立＞ (2018 2021年) という研究プロジェクトの成果として行われた。この研究事業の目的は、その 名称が言うように、日本の哲学と宗教、文化の思想の内容を日本の国外に発信す るための学術的研究と実践にある。こうした研究活動は、1974年の創立以来、宗 教間対話、文化間対話を本格的に遂行してきた南山宗教文化研究所研究活動の一 環でもある。

南山宗教文化研究所は、カトリック教会の第2次バチカン公議会が採択した「キ リス卜教以外の他宗教に対する教会の立場」(Nostra Aetate) という文書の中で闡 明された宗教間対話の精神を実践するために、カトリック修道会の神言会 (Societas Verbi Divini，英文表記はThe Society of the Divine Word、あるいは、 Divine Word Missionaries)によって創立された研究所である。同研究所は、これ まで日本国内はもちろんのこと、海外の神学者、宗教学者、哲学者らと連携し、 宗教間または文化間の対話の実践とそれに関する研究を持続的かつ重点的に推進 してきた。このような伝統は、本研究所に属する研究員はもちろん、長短期間に 
わたって研究所に滞在しながら研究を行う様々な分野の研究者によって今も引き 継がれている。

上記の研究プロジェクトを遂行するために、この研究プロジェクトの代表訳 を務めるわたしは、「韓国語で日本哲学、宗教思想を翻訳して出版する」ことにこ の研究プロジェクトの具体的な目標を設定し、それに合わせて研究活動の内容を 計画した。すなわち、「翻訳とは何か」について研究する理論的研究活動と、実際 に日本の哲学、宗教思想を韓国語に翻訳する実践的研究活動、これら二つの軸を 中心に遂行しようとした。

まず「翻訳とは何か?」という膨大なテーマへの一つのアプローチとして、私 たちは翻訳の理論的研究を遂行する研究者と長年にわたって翻訳作業をしてきた 研究者たちを南山宗教文化研究所に招待して、「翻訳する存在としての人間 (Homo Translator)」というテーマの下で国際シンポジウムを2019年に開催した。

\section{2}

前述のように、本研究プロジェクトのもう一つの中心軸は、日本の哲学、宗 教思想を韓国語に翻訳して出版すること、すなわち翻訳に関する理論的研究を実 践に移す作業だった。これには、いうまでもなく、日本の哲学、宗教思想を韓国 に紹介することにより、日本と韓国の相互間の理解に貢献するという意味が含ま れているはずである。

このためにはまず、日本の哲学と宗教思想がどの程度翻訳また紹介されてい るかという現状を分析して、資料を取りまとめてみる必要があった。そこで私 たちは、各分野の日本哲学と宗教、文学を専攻した韓国の研究者らを本研究所に 招き、現在韓国に日本の哲学と宗教が紹介されている現状に関する研究調査の結 果について発表してもらうとともに、それぞれの分野に対応する日本の研究者 たちの意見を聞く、一つのワークショップを開催することにした。そのワーク ショップの結果に基づき、私たちは実際に翻訳作業を担っていただく韓国の研究 者らに会い、具体的な翻訳作業を進めることにした。

こうした翻訳作業が本格的な軌道に乗ることができたのは、「高麗大学グロー バル日本研究院」の金孝順教授と厳仁卿教授のおかげであった。両先生との数回 にわたる打ち合わせにより、翻訳作業のための諸事項、すなわち翻訳者の選定と 交渉、翻訳のための詳細な指針の設定、翻訳の日程、翻訳作業の統一性を保つた めの共同ワークショップの開催などなどを一つずつ具体化していくことができ た。両先生の紹介により、「高麗大学グローバル日本研究院」と直接的・間接的に 関係を持っておられる日本研究者との出会いが可能になり、それにより翻訳作業 
は本格的に始動することになったのである。

この翻訳作業を円滑に進めるためには、私たちは何度も直接会って、各翻訳 者の翻訳結果を共有し互いに確認することが絶対に必要であった。そのような出 会いを通じて翻訳日程の確認、翻訳用語と文体の統一、読者層をどのように設定 するかという問題、読者のために脚注をどの程度まで付け加えるかという仔細 な問題にいたるまで、さまざまなことを相談し決定することができた。そして 場合によっては翻訳担当者を新たに交渉する必要性も提起された。南山大学と高 麗大学で数回行われたワークショップを通して、これらの翻訳作業は徐々に実 を結ぶことになったのである

\section{3}

『資料集』は聖徳太子の「十七条憲法」から始まり、日本の「仏教伝統、「禅仏教、 「浄土仏教」、儒教」、「神道」、「近代講壇哲学」、「京都学派」、「20世紀哲学」、「文 化と正体性」「侍の精神」、「女性哲学者」、「美学」、「生命倫理」などを含む、名 実ともに日本の宗教・哲学思想を網羅しながら、それに関連する資料とその資料 に対する簡略的な解説を加えたものである。それゆえ、『資料集』は、日本の思想 について研究する研究者、大学や大学院の学生はもちろんのこと、日本について 知りたいと思う一般読者の関心にも対応するものであろう。いままでも日本の 宗教・哲学について紹介する書籍は数多く出版されたが、この『資料集』のような 種類の本はまだ韓国には紹介されなかったと思う。というのは、この『資料集』 を通して、韓国人にもある程度馴染みのある日本の思想家の書いたものの原文が 紹介されているからである。もちろん、本の分量には制限があるので、すべて の思想家のすべての資料を載せるのは不可能である。それゆえ、この『資料集』 においても、ある日本の思想家が残した資料の中からもっとも核心的だろ思わ れる部分を拔粋して翻訳するしかなかったのである。そして、この「抜粋して翻 訳する」という行為こそ、すべての理解行為に含まれている解勫学的な要素が働 いているのであろう。

こうした点で、ここで一つ明記したいことがある。この『資料集』は、英語で 出版されたJapanese Philosophy: A Sourcebook (Nanzan Library of Asian Religion and Culture) (James Heisig, Thomas Kasulis, John Maraldo eds., The University of Hawaíi Press, 2011)を韓国語に翻訳したものであるが、今度の翻 訳作業においては、その「資料」を英語からではなく日本語の原文から直接に翻訳 した。すなわち、Japanese Philosophy：A Sourcebookには、日本の宗教・哲学の 資料を英語に翻訳した欧米の日本研究者の解釈的立場が含まれている。これらの 
事実は、日本の宗教・哲学の諸概念を英語に移す際に、欧米のキリス卜教的な理 解の地平が介在しているとのことを意味する。簡単な例を挙げると、「神」を ‘God'に、「法」を'Law'に英訳することにより、アジアの日本の思想体系はキリス 卜教的欧米の思想の文脈の中に位置づけられる。また、当然ながら、Japanese Philosophy：A Sourcebookの編集作業には、日本の哲学と宗教思想に対する英語 圏学者の判断基準が働いているはずであり、彼らの欧米的視点と理解が反映され ている。Japanese Philosophy:A Sourcebookの編集者や翻訳者がこうした問題 を徹底的に意識していることは、Japanese Philosophy：A Sourcebookの “Glossary (用語解説) を読むことにより明確になる。この'Glossary’の部分で、彼ら は「修行」を‘cultivation'に、「方便」を’expedient means'に英「訳」した理由について 説明をしている。場合によっては、「言霊」や「侘」をその発音に沿ってそれぞれ ‘kotodama’や'wabi'に「表記」した理由についても説明文を加えている。それゆえ、 Japanese Philosophy：A Sourcebookを韓国語に訳した『資料集』は、重訳といら問 題が最初から内在しているのである。これは、「修行」の英訳としての 'cultivation'をさらに韓国語に訳するさいに起こりうる問題のことを意味する。実 に、こうした「重訳」の問題は、必ずしも否定的なものではなく、人間の最も基 礎的な生き方としての理解・翻訳の行為に原初的に含まれている「地平の融合」と いう現象からみ机ば、きわめて自然的なことでもある。

それはともかく、『資料集』の翻訳においては、日本思想に対する英語の翻訳 をさらに韓国語に移すということに伴われうる問題を最小限に抑えるために、 Japanese Philosophy:A Sourcebookに掲載されている英文からではなく、その 英文の元である日本語の原文を見つけて韓国語に翻訳する方法を選んだ。このよ うなことは、日本語の原文のすべての資料を持っているジェームズ・ハイジッ ク博士のお力添えがなかったら不可能なことであった。英語訳には欧米の研究者 の理解が反映されているものであり、多くの場合、日本語の原文を彼らならで はの基準により抜粋あるいは短縮したものであった。それゆえ、それに該当す る日本語原文を一つ一つ確認して韓国語に翻訳することは長い時間と努力を要す ることであり、場合によっては不可能な作業でもあったといえよう。が、八イ ジック博士のお力添えにより、時間と労力を大幅に節約することができたであ る。

このように、この『資料集』の出版には、英語圏の日本研究者の日本思想に対 する理解をへたものである。このような事実は、この『資料集』の「限界」ともい えるものではあるが、逆にいうならば、『資料集』は、日本の思想を韓国語に紹 介するという意味をもつと同時に、英語圏の研究者らの日本理解の断面を垣間見 ることができる良い機会をも提供するのである。すべての理解の行為に内在す る解釈学的の現象が、『資料集』を通しても明らかになったともいえよう。 
『資料集』が韓国でどのように受け入れられ、どのような反響が聞こえてくる のか。『資料集』の翻訳作業にご協力いただいた日本と韓国の同僚らとともに、期 待してみたいところである。

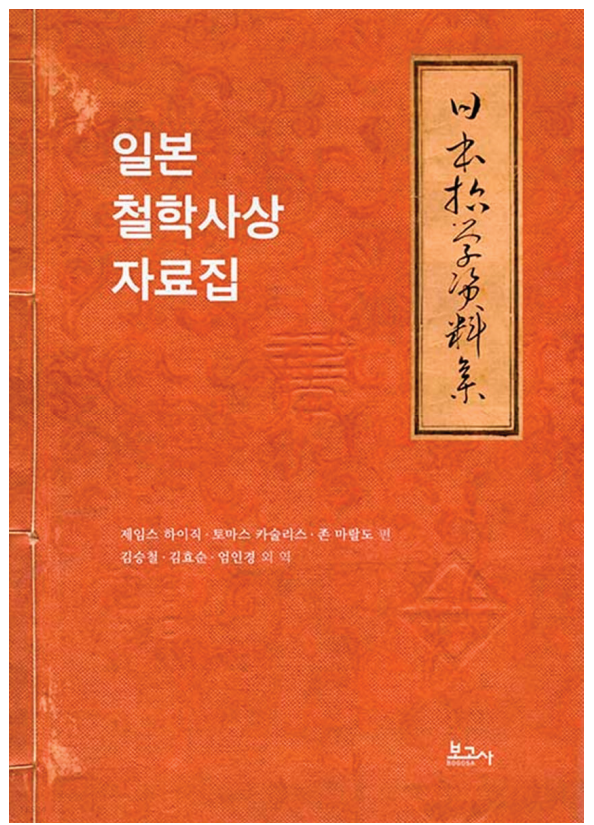

『日本哲学思想資料集』(2021.10) 